\title{
UVA enhancement of carbon fixation and resilience to UV inhibition in the genus Pseudo-nitzschia may provide a competitive advantage in high UV surface waters
}

\author{
Claudia Mengelt* ${ }^{*}$ Barbara B. Prézelin \\ Department of Ecology, Evolution \& Marine Biology, University of California Santa Barbara, Santa Barbara, \\ California 93106, USA
}

\begin{abstract}
The present study compares the Ultraviolet A (UVA: 320 to $400 \mathrm{~nm}$ ) enhancement of in situ carbon fixation relative to Ultraviolet B (UVB: 280 to $320 \mathrm{~nm}$ ) inhibition for a community dominated by the diatom genus Pseudo-nitzschia with other mixed phytoplankton communities in the Santa Barbara Channel in June 1998. At the time, a widespread bloom of toxic P. australis and toxinrelated mortality among marine mammals occurred between San Francisco and the Southern California Bight. We sought out the location of the Pseudo-nitzschia bloom during a cruise designed to quantify the variability in ultraviolet (UV) effects on primary productivity in diverse phytoplankton communities. Replicate phytoplankton samples were incubated in situ at a depth of $5 \mathrm{~m}$ to determine the sensitivity of carbon uptake and pigmentation in 7 distinct spectral light treatments, in which shorter wavelengths of UV radiation are progressively removed. Carbon fixation for the Pseudonitzschia-dominated community was enhanced relative to photosynthetically available irradiance $(\mathrm{PAR}, 400$ to $700 \mathrm{~nm})$ in all PAR + UVA treatments and enhancement appeared maximal at $15 \%$ (p < $0.01, t$-test) in the shortest UVA wavelength treatment $(>318 \mathrm{~nm})$. In other mixed phytoplankton communities, UVA enhancement of carbon fixation was only observed for the long-wavelength treatments (340 to $400 \mathrm{~nm}$ ), whereas inclusion of wavelengths between 320 and $340 \mathrm{~nm}$ had an inhibitory effect on carbon fixation. UVB photoinhibition relative to maximum production rates was comparable for all 3 communities. Based on our in situ observations, we conclude that Pseudo-nitzschia sp, although susceptible to UVB inhibition, is well adapted to utilizing the entire UVA portion of the spectrum to enhance carbon fixation. This might also enable algal species of the genus Pseudonitzschia to occupy shallower portions of the water column, where the full spectrum of UVA and PAR penetrates and inhibits photosynthesis of other mixed algal assemblages.
\end{abstract}

KEY WORDS: Photophysiology · Ultraviolet effect · Harmful algal bloom · Diatoms · Photosynthesis · Pseudo-nitzschia sp.

- Resale or republication not permitted without written consent of the publisher

\section{INTRODUCTION}

In June 1998, a toxic diatom bloom of the genus Pseudo-nitzschia was reported for the first time in the Santa Barbara Channel (Trainer et al. 2000). Such events in the Monterey Bay area have resulted in increased mortality among sea lions (Work et al. 1993, Gulland
1999, Scholin et al. 2000). In the short time since the discovery of domoic acid (DA) in diatoms, many vectors for the transfer of the toxin have been described including krill, anchovies, and many benthic invertebrates (Trainer et al. 2000, Lefebvre et al. 2001, Bargu et al. 2003). Given the broad range of marine organisms susceptible to DA poisoning, considerable concern has 
arisen that Pseudo-nitzschia sp. blooms could have farreaching negative impacts on coastal fisheries. This concern has spurred an intense effort to elucidate environmental factors resulting in Pseudo-nitzschia sp. blooms and in particular, controls on the variable cellular toxicity (Bates et al. 1998, Mos 2000).

While much is known about nutrient controls on Pseudo-nitzschia sp., growth, and cellular toxicity (Bates et al. 1998, Maldonado et al. 2002), the photophysiology of this algal genus has not yet been examined in detail. Hargraves et al. (1993) found P. multiseries growth to be unaffected by UVB (280 to $320 \mathrm{~nm}$ ). Additionally, laboratory work with the polar species $P$. seriata demonstrates photosynthetic enhancement of carbon fixation with the addition of UVB to treatments with UVA + PAR (UVA: 320 to $400 \mathrm{~nm}$; PAR: 400 to $700 \mathrm{~nm}$ ) (Nilawati et al. 1997). In another study P. multiseries exhibits the ability to grow well with low levels of light, potentially explaining the seasonal dominance of this species in the fall in the Prince Edward Island region (Pan et al. 1996). These studies suggest a high UV tolerance by this diatom genus as well as the potential to grow well under a wide range of light conditions.

However, these results are in contrast to most reports in which UV light $(<400 \mathrm{~nm})$ inhibits photosynthesis of temperate and polar marine phytoplankton (Cullen \& Lesser 1991, Helbling et al. 1992, Smith et al. 1992, Lesser et al. 1994, Neale et al. 1994). Some studies ascribe a large proportion of the UV photoinhibition to the UVA spectrum (Smith et al. 1992, Holm-Hansen et al. 1993). In general, UVA is known to play a role in photo-assisted repair of nucleic acid lesions (Mitchell \& Karentz 1993) and can moderate the negative effects of UVB in culture (Quesada et al. 1995). Hence, the net effect on carbon fixation in the UVA region is the resulting balance between photoinhibtion and photorepair mechanisms (Prézelin et al. 1994). It is also well-established that the sensitivity among algal species appears to vary greatly (Karentz et al. 1991, Vincent \& Roy 1993), which does not appear to be group-specific, given the broad range of UV responses for different diatom species (Cullen \& Lesser 1991, Helbling et al. 1992, Lesser et al. 1994, Buma et al. 1996, Nilawati et al. 1997, Zudaire \& Roy 2001). The increase in UVB irradiance reaching the ocean due to ozone depletion (Madronich et al. 1998) therefore has the potential for species selection (Bothwell et al. 1993).
The present study compares the UV sensitivity of carbon fixation by a Pseudo-nitzschia-dominated algal community to the sensitivity of mixed algal assemblages in the surrounding waters. It intends to examine whether the UV tolerance observed in the laboratory for species of this genus is also observed in situ.

\section{MATERIALS AND METHODS}

Cruise and sample location. Field experiments were conducted aboard the RV 'Point Sur' from June 7 to 20, 1998 in the Santa Barbara Channel and south of the Channel Islands, California, USA. The first sampling station was situated near the Gaviota coast just east of Pt. Conception, a location of frequent upwelling, where we encountered the Pseudo-nitzschia bloom (Fig. 1). This geographical location was occupied on 2 consecutive days, June 8 and 9. The second location, south of Santa Cruz Island, in a warm water mass flowing northward along the California coast, was visited on June 13.

Hydrographic sampling. A Sea-Bird CTD was used for measuring vertical profiles of physical, optical, and chemical water properties. CTD profiles were conducted before beginning an experiment and every 2 to $4 \mathrm{~h}$ during an experiment to determine pressure in decibar $(\mathrm{db})$, temperature $\left({ }^{\circ} \mathrm{C}\right)$, conductivity $\left(\mathrm{S} \mathrm{m}^{-1}\right)$, PAR irradiance $\left(\mu\right.$ Einsteins $\left.\mathrm{cm}^{-2} \mathrm{~s}^{-1}\right)$, percent transmission at $660 \mathrm{~nm}$, chlorophyll fluorescence (relative units), and salinity (ppt). The temperature and salinity data obtained from the CTD measurements were used to calculate the derived properties of density $\left(\sigma_{\mathrm{T}}\right)\left(\mathrm{kg} \mathrm{m}^{-3}\right)$.

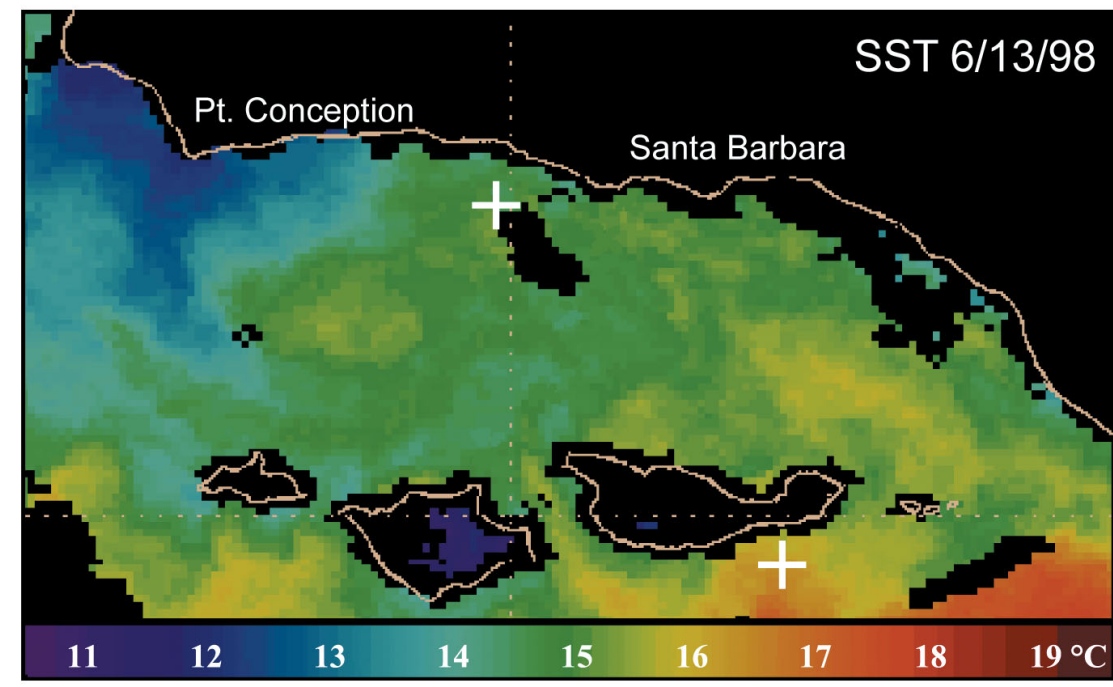

Fig. 1. Satellite image of the sea surface water temperature distribution in the Santa Barbara Channel on June 13, 1998. The station locations are marked with white crosses. The cross closest to the mainland (Gaviota coast line) corresponds to the location of the June 8 and 9 incubations, and the cross south of the island (Santa Cruz island) marks the station occupied during the June 13 experiments 
Light measurements. Surface irradiance was continuously measured each day with a Biospherical GUV510B multi-filter radiometer. The instrument detects integrated PAR and irradiance at 4 wavebands $(10 \mathrm{~nm}$ FWHM bandwidth) in the UV portion of the solar spectrum: at 305, 320, 340, and $380 \mathrm{~nm}$. Flux of integrated PAR is measured and reported as $\mu$ Einsteins $\mathrm{m}^{-2} \mathrm{~s}^{-1}$ $\left(\mu\right.$ Ein $\left.\mathrm{m}^{-2} \mathrm{~s}^{-1}\right)$. Flux of UV is measured as $\mu$ Watts $\mathrm{cm}^{-2}$ $\mathrm{nm}^{-1}$ and converted to $\mu$ Ein $\mathrm{m}^{-2} \mathrm{~s}^{-1}$. Data were recorded at 2 to 3 samples per second and averaged over $5 \mathrm{~min}$ using the Biospherical data acquisition software (DASWIN).

In-water spectral irradiance was measured at the same wavelengths as surface irradiance by employing a Biospherical PUV-510B. Vertical profiles down to $50 \mathrm{~m}$ were conducted every $2 \mathrm{~h}$ in close proximity to the underwater sample incubators. Simultaneous subsurface PUV and surface GUV measurements, at a sampling rate of 2 to 3 times per second, were recorded and used to determine percent light levels. In-water irradiance measurements were used to calculate attenuation coefficients $\left(k_{\lambda}, \mathrm{m}^{-1}\right)$ for PAR, 305, 320, 340, and $380 \mathrm{~nm}$. Full spectral underwater UV field and integrated PAR irradiance were derived from $k_{\lambda}$ using the Solar Light In-water Calculations code (for further details on the light measurements, derivation of full spectral underwater light fields, and the Solar Light In-water Calculation code see http://lifesci.ucsb.edu/ eemb/labs/prezelinpublications.html).

Sample collection and incubation. Water samples for incubations were collected before sunrise (or in the morning for the half-day incubations) at a $5 \mathrm{~m}$ depth using 121 Niskin bottles mounted on a CTD rosette system and prefiltered using a $333 \mu \mathrm{m}$ mesh filter to minimize grazing. Initial samples were taken for fluorometric determination of chlorophyll a (chl a), pigment determination via high performance liquid chromatography (HPLC), and determination of net phytoplankton species composition using light microscopy. The water for carbon uptake experiment was spiked with ${ }^{14} \mathrm{C}$-labeled $\mathrm{HCO}^{-}$and incubated in $230 \mathrm{ml}$ aliquots in Whirlpak polyethylene bags, some of which were used for the dark sample. Five replicate bags were used for each of the 7 spectral treatments and placed in a free-drifting in situ incubator at a $5 \mathrm{~m}$ depth. Additional sample bags were filled without the addition of ${ }^{14} \mathrm{C}$-labeled $\mathrm{HCO}^{-}$and placed in the same spectral light treatments for pigment determination. Transmission filters were designed to create 7 spectral treatments, cutting off progressively shorter wavelengths of the UV spectrum (Fig. 2). The treatments were labeled at the wavelength above, at which $50 \%$ or more light is transmitted: $>295,>309,>318,>328$, $>341,>382$, and $>403 \mathrm{~nm}$ (for additional details of incubator and filter design, see Prézelin et al. 1994). Free-drifting incubators were deployed at the location where water samples were collected and incubated at a $5 \mathrm{~m}$ depth during the lit portion of the day for the following durations: 6.4 and $11.3 \mathrm{~h}$ on June $8,4.2$ and $11.5 \mathrm{~h}$ on June 9 , and 4.5 and $11.4 \mathrm{~h}$ on June 13. After recovery of incubators, the content of replicate bags was kept in the dark before analysis.

Sample analysis. Photosynthetic rate determination:

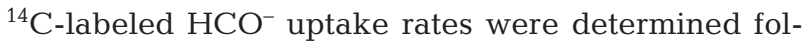
lowing the procedure detailed in Prézelin et al. (1994). Following incubation, samples were filtered onto $0.45 \mu \mathrm{m}$ filters and placed in scintillation vials, to which $10 \mathrm{ml}$ of scintillation fluor (Ecoscint, National Diagnostics) was added. Radioactivity was measures on a liquid scintillation counter (Beckman). The percent UV-enhancement of photosynthesis was calculated relative to the PAR (400 nm cut-off transmission filter) treatment based on the differential hourly carbon uptake rates. The percent UV-inhibition of photosynthesis was determined relative to the spectral treatment, which resulted in the maximum hourly carbon uptake rate. A 2-tailed $t$-test was performed to determine the probability that the spectral treatment resulted in no difference in carbon fixation relative to PAR and UV-spectral treatments.

Pigment determination: Chlorophyll and carotenoid concentrations were determined by HPLC at the beginning and end of every experiment. Due to the small

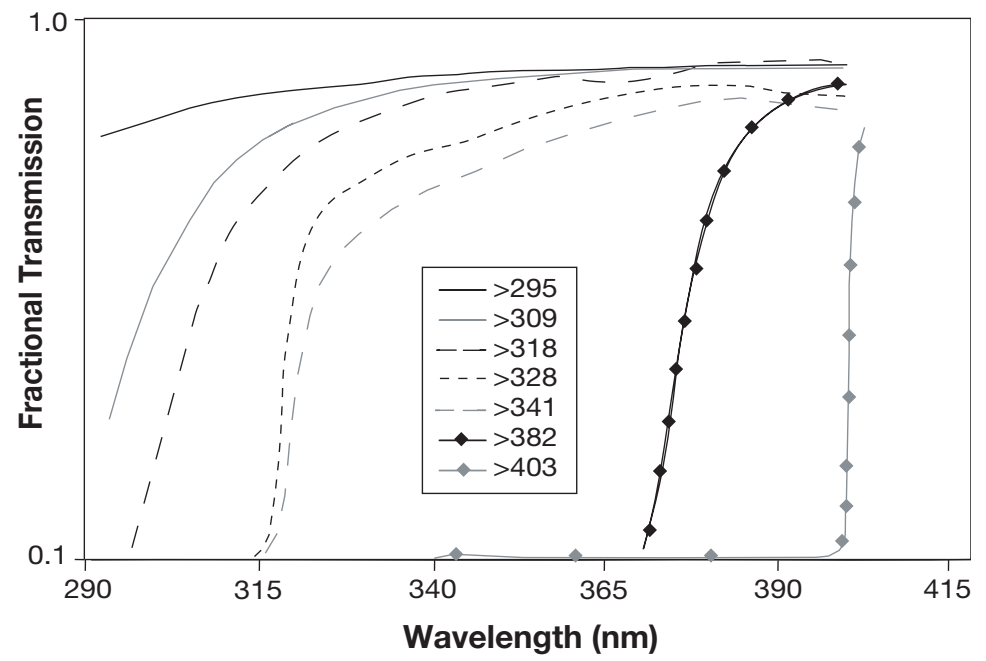

Fig. 2. Fractional light transmission through the different filters used to selectively block shorter wavelength in the ultraviolet. The 7 distinct light treatments are marked with the corresponding wavelength above which fractional light transmission is 0.5 or greater 
incubation bags and the large filter volume required to determine pigment concentrations in field samples, samples from replicate treatments were combined into 1 sample prior to filtration. Hence, each pigment value represents an average treatment effect; however, the standard deviation between treatments could not be determined for the pigment values. Samples were filtered onto $0.4 \mu \mathrm{m}$ polycarbonate filters (Osmonics, Poretics Products) and stored on dry ice during the cruise and in $\mathrm{a}-80^{\circ} \mathrm{C}$ freezer upon return to shore. Samples were extracted in $90 \%$ acetone for $24 \mathrm{~h}$ in the dark at $-20^{\circ} \mathrm{C}$. Prior to analysis, $0.25 \mathrm{ml}$ of internal standard canthaxanthin was added (Fluka). Samples were injected using a Shimadzu SIL-10 ADVP autosampler onto a $25 \mathrm{~cm}$ Alltech Alltima C18 analytical column, which was kept at room temperature. Peak separation was obtained with the solvent system as described in Wright \& Jeffrey (1997) and delivered by a Hitachi L7100 pump. A Spectra System UV2000 UV/VIS detector (Thermo Separation Products) was used to measure peak absorbance at $336 \mathrm{~nm}$ in order to quantify pigment concentrations. The system was calibrated using pure pigment standards (VKI) (measurement error = $5 \%$ ). The following chemotaxonomic pigments were measured: chl $a, b$ and $c$, peridinin (PERI), 19'butanoyloxyfucoxanthin (BUT), fucoxanthin (FUCO), 19'hexanolyoxyfucoxanthin (HEX), prasinoxanthin (PRAS), alloxanthin (ALLO), and zeaxanthin (ZEA). In addition to chemotaxonomic pigment determination, samples were examined under light microscopy in the field to determine the most dominant phytoplankton species or genus in each sample.

\section{RESULTS}

\section{In situ observations}

\section{Chlorophyll a}

Satellite images reveal the mesoscale and temporal dynamics of the phytoplankton bloom in the Santa Barbara Channel and along the central California coast during early June 1998 (Fig. 3). The blooms were dominated by Pseudo-nitzschia australis along much of the coast just prior to our cruise (Trainer et al. 2000). By June 4, a large and dense phytoplankton bloom had developed in the western half of the Santa Barbara Channel with surface chl a concentrations above $1.25 \mathrm{mg} \mathrm{chl} \mathrm{a} \mathrm{m} \mathrm{m}^{-3}$ in the center of the bloom (Fig. 3A). Trainer et al. (2000) observed a widespread P. australis bloom on June 4 and 5, along the Gaviota and Santa Barbara coasts, with associated high DA concentrations. The high phytoplankton biomass was confined to the Santa Barbara Channel. Between June 4 and 8, the intensity of the bloom declined significantly although patches of elevated chl a could still be seen at the west end of the Channel, consistent with patterns of local eddy circulation (Fig. 3B). However, the biomass was relatively low at the experimental site on June 8 and 9 (Fig. 3B,C). Light microscopic observations confirmed that the community was still dominated by the genus Pseudo-nitzschia. By June 13, chl a concentrations throughout the region had increased again and were above $1.0 \mathrm{mg}$ chl a m $\mathrm{m}^{-3}$ (Fig. 3D).

Vertical distribution of temperature, density, and chlorophyll a

On June 8, the temperature in the upper $20 \mathrm{~m}$ of the water column was fairly uniform $\left(12.7\right.$ to $\left.12.8^{\circ} \mathrm{C}\right)$, suggesting recent mixing (Fig. 4A). The depth of the $11^{\circ} \mathrm{C}$ isotherm, indicative of nutrient-rich deep water of the California Current System (Collins et al. 2000), was shoaling during the day. $\mathrm{Chl}$ a concentrations ranged from $0.17 \mu \mathrm{g} \mathrm{l}^{-1}$ at depth to a maximum of $0.98 \mu \mathrm{g} \mathrm{l}^{-1}$ at a $14 \mathrm{~m}$ depth (Fig. 4B). The phytoplankton biomass appeared to be confined to the upper mixed layer on June 8 , which was shallow enough to expose $46 \%$ of the chl a biomass in the upper $100 \mathrm{~m}$ of the water column to PAR, UVA and UVB radiation. Coinciding with the shoaling of the thermocline, the chl a maximum became shallower later in the day (data not shown), and was observed at $7 \mathrm{~m}$ at 14:30 h. The following day, the water column at the same geographic location was stratified from the surface to a $100 \mathrm{~m}$ depth and water temperatures in the upper $20 \mathrm{~m}$ had increased, and ranged from 13.3 to $14.8^{\circ} \mathrm{C}$ (Fig. $4 \mathrm{C}$ ). Biomass ranged

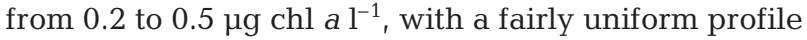
down to $100 \mathrm{~m}$ (Fig. 4D). On June 13, at the station south of Santa Cruz Island, water temperatures were higher, ranging from 14 to $16.5^{\circ} \mathrm{C}$ in the top $20 \mathrm{~m}$ (Fig. 4E). The water column was again stratified from the surface to a $100 \mathrm{~m}$ depth, with a particularly strong thermo- and pycnocline at $20 \mathrm{~m}$. Biomass was elevated, with chl a values ranging from 0.2 to $1.5 \mu^{-1}$ (Fig. 4F). Chl a values peaked slightly above the thermocline and decreased with depth in the thermocline. As on June 8, some of the phytoplankton biomass associated with the chl a maximum was shallow enough to be exposed to PAR, UVA, and UVB.

\section{In situ light exposure}

The light reaching the ocean's surface was spectrally integrated over 3 portions of the solar spectrum: PAR, UVA, and UVB (Fig. 5A-C). On June 8, a marine layer decreased the incident radiation throughout the solar 
A
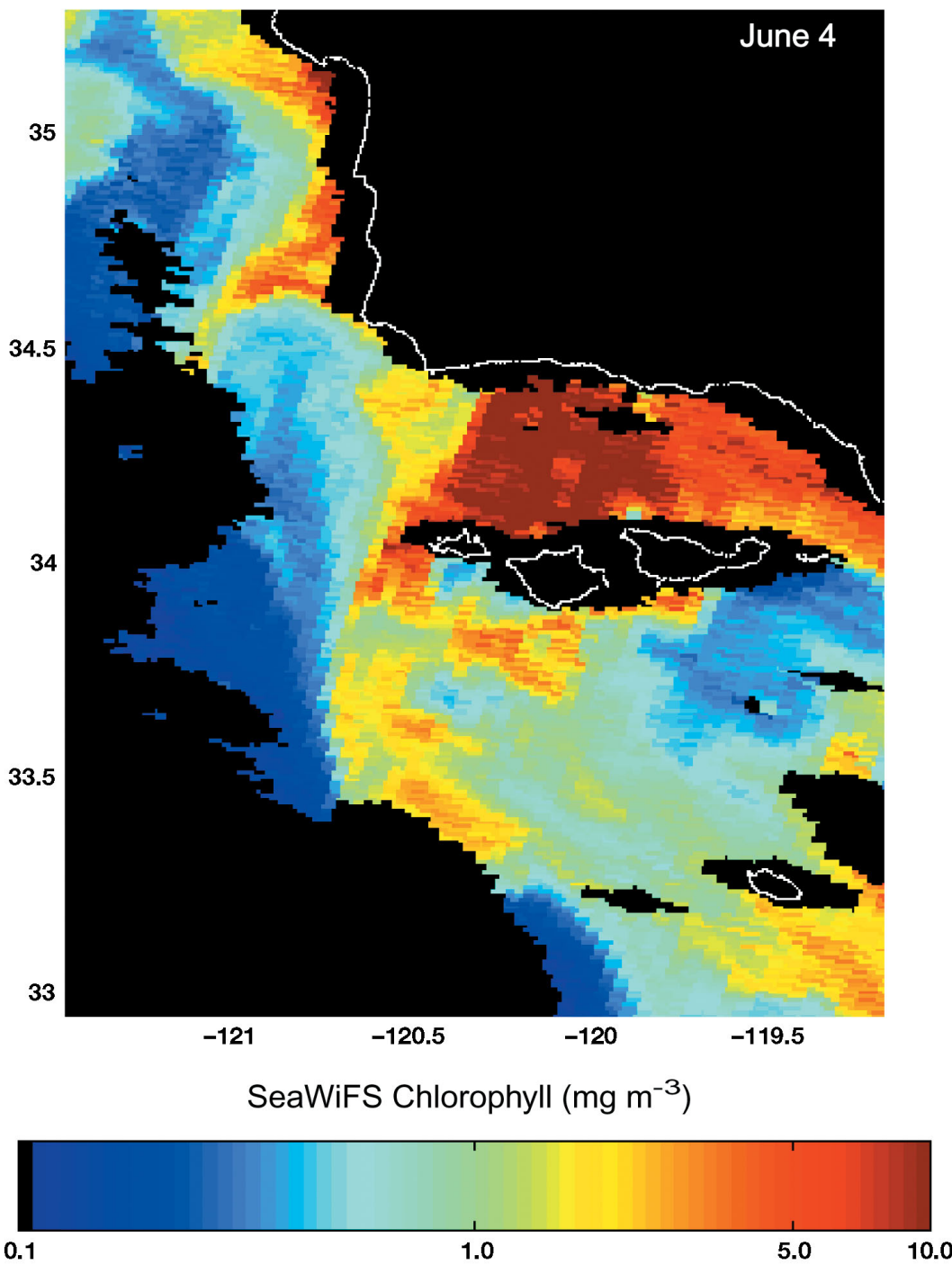

B
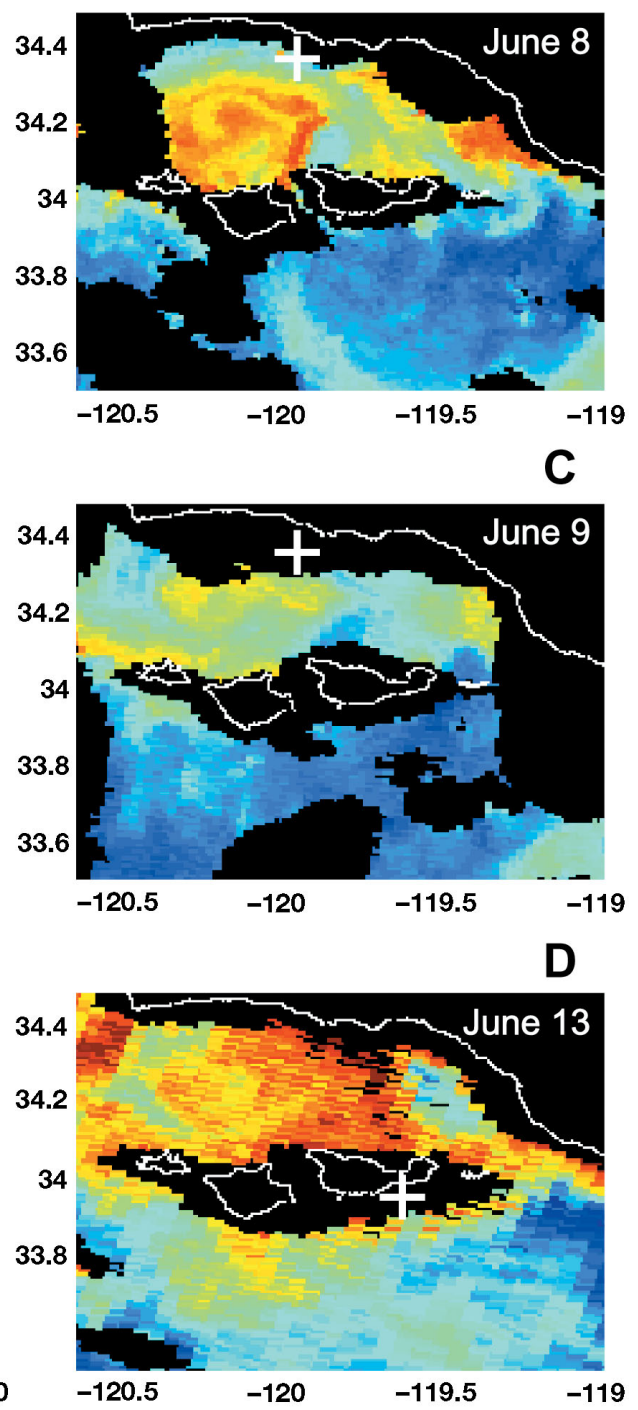

Fig. 3. Satellite images of the surface chlorophyll distribution (A) along the Central Californian coast on June 4, 1998, (B) in the Santa Barbara Channel on June 8, (C) on June 9, and (D) on June 13, 1998. White crosses (B-D) correspond to the station locations on the respective dates

spectrum in the first $3 \mathrm{~h}$ of the day relative to June 13. However, by 10:00 h, solar irradiance on June 8 and 13 were similar and approached modeled clear sky values for that day. On June 9, PAR, UVA, and UVB were decreased by 20 to $50 \%$ throughout the day relative to the other 2 days due to the persistent marine layer. The decrease in PAR due to the marine layer was greater than the decrease in UVA and UVB.

The light reaching the depth of our experimental drifters at $5 \mathrm{~m}$ was a result of both differences in cloud cover and absorption properties of the water. Due to the marine layer on June 9, the light the experiment at a $5 \mathrm{~m}$ depth received on June 9 was on average half of the irradiance measured at the same depth on June 8 and 13 (Fig. 5D-F); therefore, it will be considered to be a low light (LL) treatment when discussing the biological response for the June 9 experiments. On June 8, some cloud cover was present in the early morning. However, integrated light exposure was similar on June 8 and 13; therefore, experiments on both days can be considered to be high light (HL) treatments.

\section{Experimental results}

\section{Community composition}

In order to determine the most dominant phytoplankton groups, the relative amount of group-specific carotenoids in each initial sample were compared. 
A

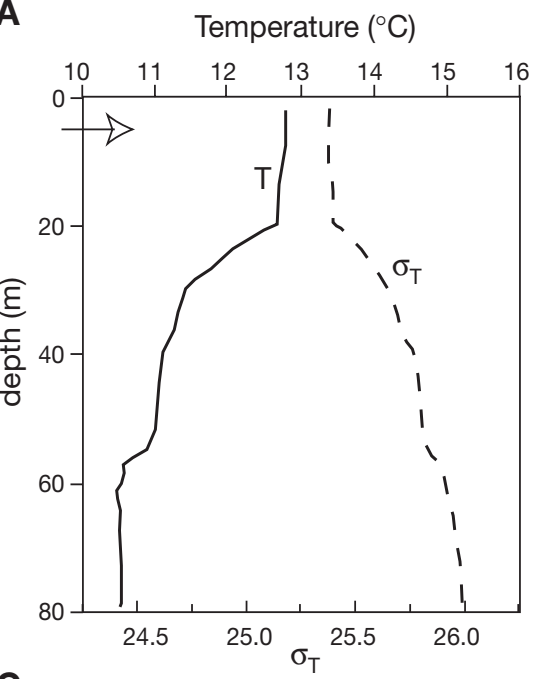

C

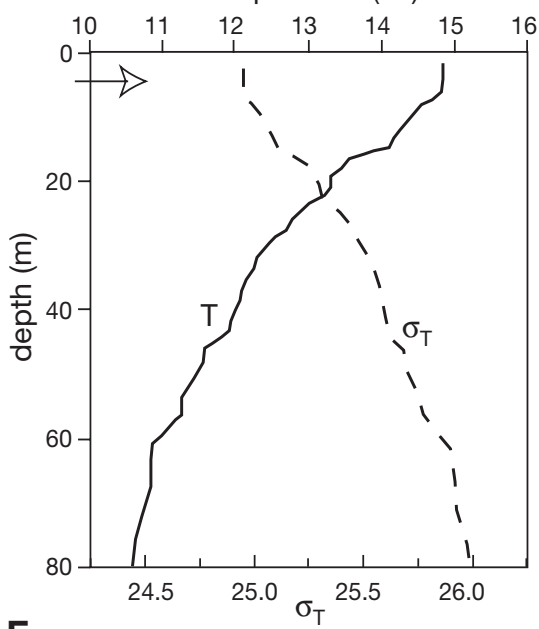

E

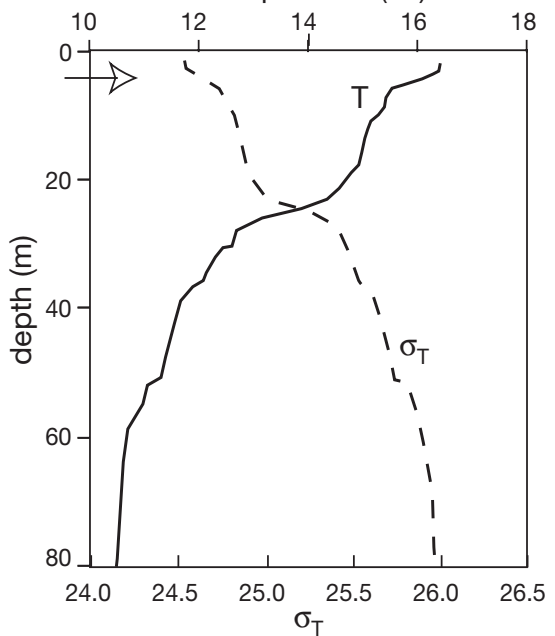

B

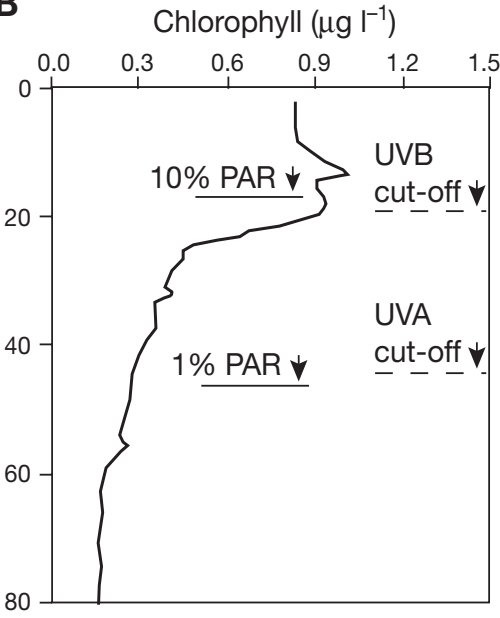

D

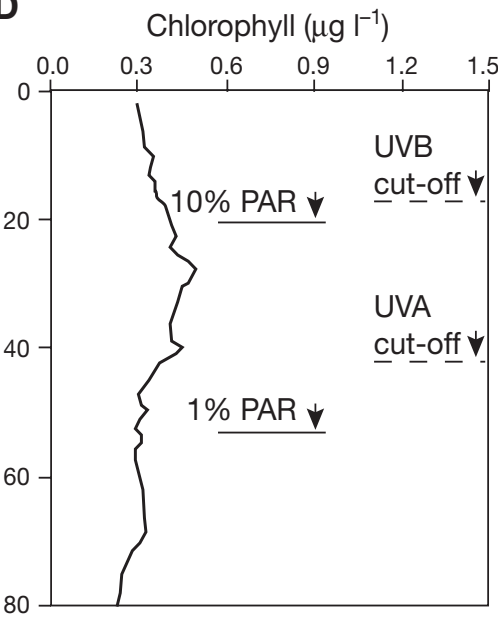

$\mathbf{F}$

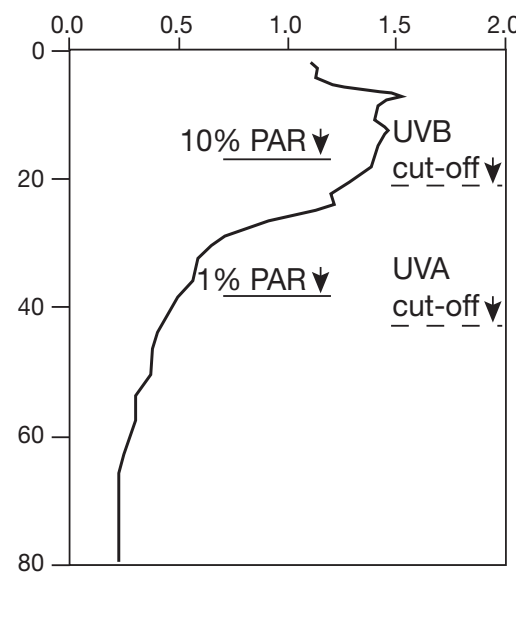

Fig. 4. Depth profiles for temperature, density $\left(\sigma_{\mathrm{T}}\right)$, and chl a $(\mathrm{A}, \mathrm{B})$ on June 8 , on (C, D) June 9 and on (E, F) June 13, 1998. The open symbol arrow in (A), (C) and (E) indicates the depth of the experimental drifters. The closed symbol arrows in (B), (D) and (F) mark the light depth below which UVB or UVA are fully attenuated as well as the depth of the $10 \%$ and $1 \%$ PAR level

FUCO, a diagnostic pigment for diatoms, had the highest concentration on June 8, contributing 68 and $70 \%$ of the total weight of all the marker pigments in the full and half-day incubations, respectively (Fig. 6). The diatom community was almost entirely composed of chains of large Pseudo-nitzschia sp., which was the most dominant algal species $(90 \%$ of net phytoplankton). The diagnostic pigments HEX and BUT for the flagellates, prymnesiophytes and chrysophytes contributed a combined 17 and $15 \%$ of the total pigment concentration on June 8 and were the second most common algal group (Fig. 6). Other minor components of the diagnostic carotenoids on that day were chl $b(8 \%)$, ZEA (5\%), and PERI (3\%). Despite our efforts to remain in the same watermass, the following day, the FUCO pigment contribution to the total diagnostic carotenoids had decreased to less than $40 \%$ in both the fullday and half-day incubations (Fig. 6). The diatom assemblage contained representatives of the genera Pseudonitzschia, Thalassiosira and Chaetoceros. Based on the pigment concentrations, the prymnesiophytes and chrysophytes were equally prevalent $(36 \%)$ as the diatoms during the full-day incubation on June 9, followed by the picoplankton (ZEA) and chlorophytes (chl b). Dinoflagellates, as indicated by PERI concentrations, were again the least abundant component. The mixed assemblage on June 13 during the full-day incubation appeared to be dominated by the flagellates, followed by diatoms, and thirdly by chlorophytes. During the half-day incubation, the diatoms and chlorophytes were the most dominant groups followed by the flagellates. The picoplankton and dinoflagellates were only a minor component in both incubations. The diatoms were comprised mostly of members of the genus Chaetoceros.

\section{Chlorophyll a biomass}

The decrease in total chl a biomass compared to the initial sample during the incubation at $5 \mathrm{~m}$ depths appeared to be spectrally independent 

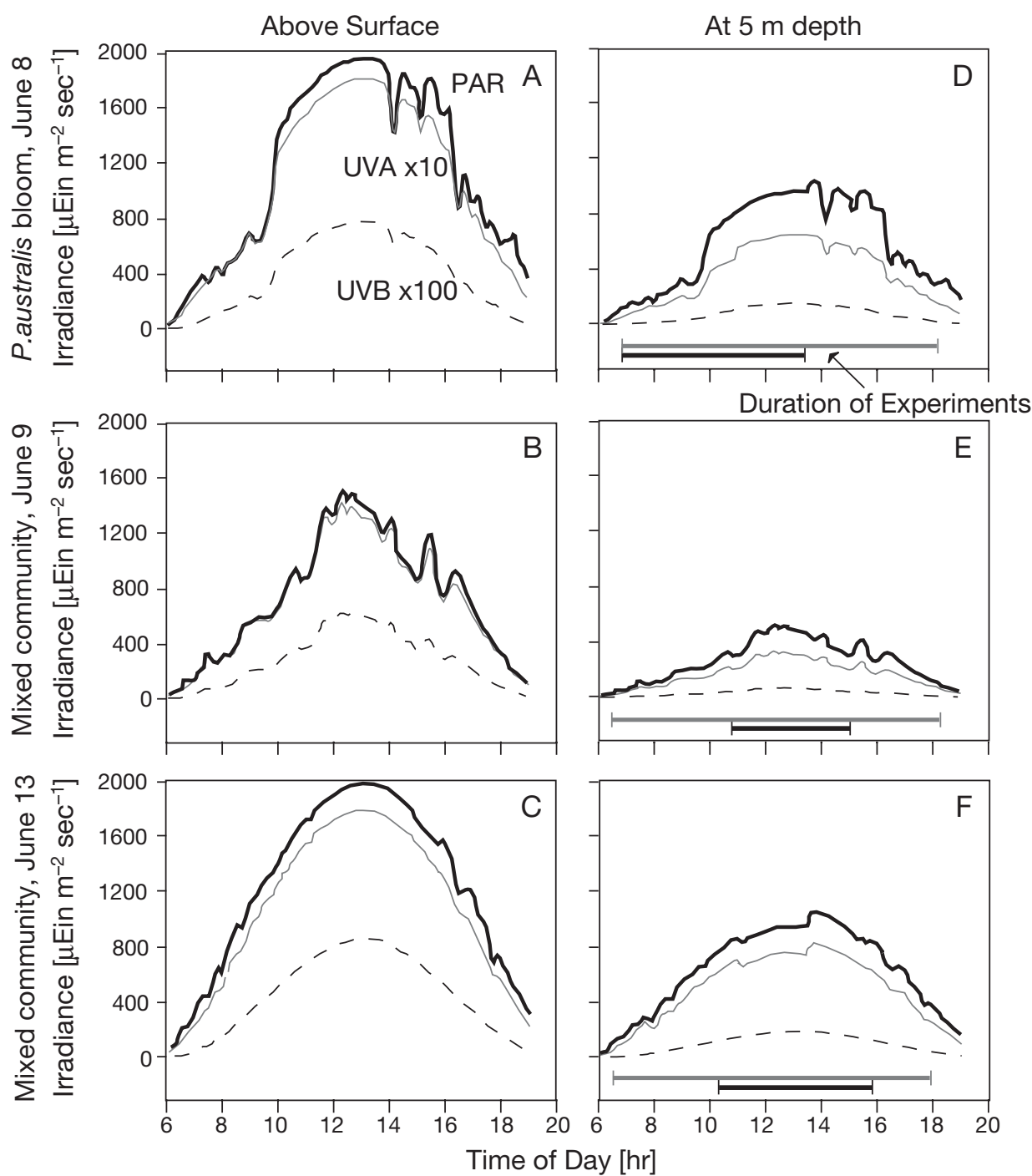

Fig. 5. Solar PAR, UVA, and UVB irradiance reaching the ocean's surface (A) on June 8, (B) on June 9, and (C) on June 13,1998 over the course of the day. The PAR, UVA, and UVB irradiance reaching the incubations at a $5 \mathrm{~m}$ depth is shown for (D) June 8, (E) June 9, and (F) June 13. The light and dark gray bars at the bottom of (D)-(F) symbolize the time span of the full day and the short-term incubations, respectively. In order to fit on the same scale, UVA and UVB values were multiplied by 10 and 100 , respectively

(Fig. 7A,B). This was the case in both the full-day (Fig. 7A) and half-day experiments (Fig. 7B). During the full-day experiment on June 8, chl a decreased on average by $20 \%$ for all spectral treatments, except for the PAR treatment, in which a larger decrease was observed. Despite the lower irradiance on June 9 , chl a decreased by approximately $60 \%$ for all treatments. The most severe decrease in chl $a$, averaging $80 \%$ for all spectral treatments, was observed on June 13, the day with the greatest light exposure. Similar patterns of chl a loss were detected during the half-day incubations, with an average loss of $18 \%$ on June 8 , indicating that the loss of chl a during the full-day incubation occurred in the initial hours of exposure (Fig. 7B). The incubations on June 9 and 13 were incubated for approximately $4 \mathrm{~h}$ centered around solar noon, which resulted in a wavelength-independent average loss of chl a by 50 and $75 \%$, respectively.

\section{In situ primary production}

Primary productivity, as determined by ${ }^{14} \mathrm{C}$-uptake, was measured using different spectral light treatments (Table 1) and compared to the primary productivity in the PAR treatment (i.e. irradiance $>403 \mathrm{~nm}$ ) to estimate the net effect of UV radiation (Fig. 8A,B, Table 2). The net UV effect can be comprised of any combination of UVB inhibition $\left(I_{\mathrm{UVB}}\right)$, UVA inhibition $\left(I_{\mathrm{UVA}}\right)$ and UVA enhancement ( $\left.E_{\text {UVA }}\right)$ (Prézelin et al. 1994). In order to assess the total inhibition of maximum in situ primary productivity, we compared primary productivity at the different spectral light treatments to the maximum primary productivity measured (Fig. 8C,D). In 4 of the 6 experiments, the maximum rate of primary productivity was observed in treatments that included some portion of the UVA spectrum (Table 1).

During the full-day experiments with the Pseudonitzschia sp. community (June 8), the amount of carbon 


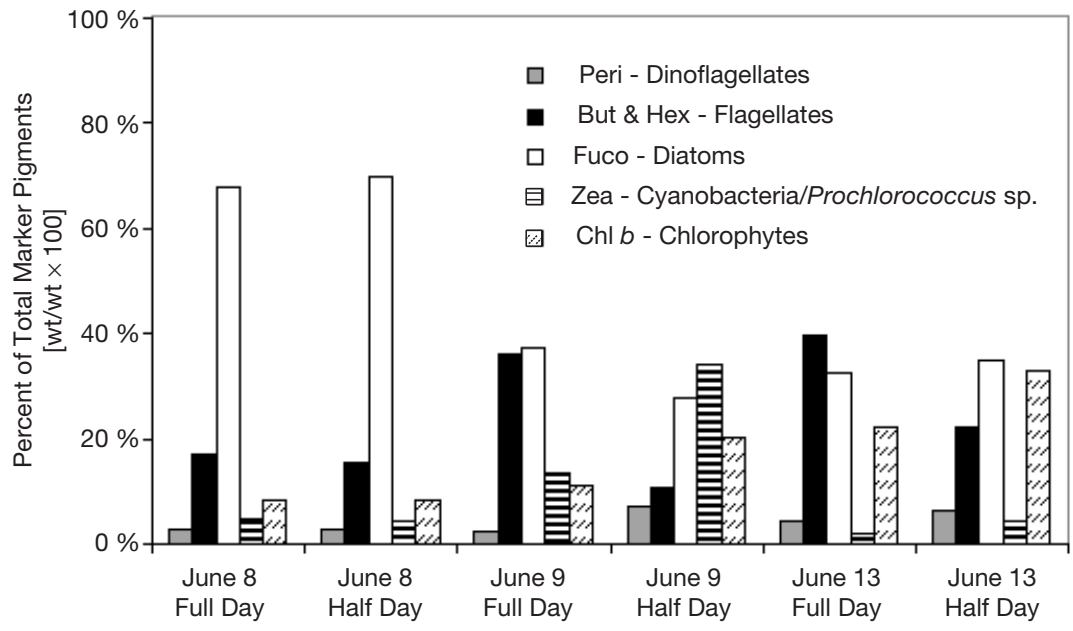

Fig. 6. Phytoplankton community composition based on relative abundance of group-specific carotenoids (wt pigment [wt (PERI + BUT + HEX + FUCO + ZEA $+\mathrm{chl} b)]^{-1}$ ) in the initial sample for each experimental incubation on June 8,9 and 13, 1998

Table 1. Average hourly carbon fixation rates $\left(\mathrm{mg} \mathrm{C} \mathrm{m}^{-3} \mathrm{~h}^{-1}\right)$ in each spectral light treatment $(>295,>309,>318,>328,>341,>382,>403 \mathrm{~nm}), \pm 1 \mathrm{SD}$, and the number of samples per average (n).

\begin{tabular}{|lcccccc|}
\hline \multirow{2}{*}{ Treatment } & $\begin{array}{c}\text { June } 8 \\
\text { Full day }\end{array}$ & $\begin{array}{c}\text { June } 8 \\
\text { Half day }\end{array}$ & $\begin{array}{c}\text { June } 9 \\
\text { Full day }\end{array}$ & $\begin{array}{c}\text { June } 9 \\
\text { Half day }\end{array}$ & $\begin{array}{c}\text { June } 13 \\
\text { Full day }\end{array}$ & $\begin{array}{c}\text { June } 13 \\
\text { Half day }\end{array}$ \\
\hline$>295$ & 2817.1 & 2595.6 & 461.4 & 1273.4 & 1066.6 & 1265.7 \\
$\pm 1 \mathrm{SD} ; \mathrm{n}$ & $\pm 302.1 ; 6$ & $\pm 286.6 ; 6$ & $\pm 43.6 ; 8$ & $\pm 131.9 ; 8$ & $\pm 188.4 ; 6$ & $\pm 169.0 ; 10$ \\
$>309$ & 2979.5 & 2410.2 & 507.2 & 1258.9 & 1111.4 & 1310.3 \\
$\pm 1 \mathrm{SD} ; \mathrm{n}$ & $\pm 71.2 ; 5$ & $\pm 123.5 ; 3$ & $\pm 41.1 ; 5$ & $\pm 82.6 ; 5$ & $\pm 160.7 ; 5$ & $\pm 12.1 ; 5$ \\
$>318$ & 3380.9 & 3004.3 & 478.8 & 1277.0 & 1135.6 & 1362.8 \\
$\pm 1 \mathrm{SD} ; \mathrm{n}$ & $\pm 69.9 ; 4$ & $\pm 11.0 ; 3$ & $\pm 30.1 ; 5$ & $\pm 68.9 ; 4$ & $\pm 138.6 ; 3$ & $\pm 52.3 ; 4$ \\
$>328$ & 3264.1 & 2994.3 & 496.6 & 1397.7 & 1187.3 & 1451.1 \\
$\pm 1 \mathrm{SD} ; \mathrm{n}$ & $\pm 164.1 ; 5$ & $\pm 95.1 ; 4$ & $\pm 21.1 ; 5$ & $\pm 160.7 ; 5$ & $\pm 109.0 ; 5$ & $\pm 22.4 ; 5$ \\
$>341$ & 3123.7 & 2919.0 & 550.5 & 1574.7 & 1309.3 & 1657.7 \\
$\pm 1 \mathrm{SD} ; \mathrm{n}$ & $\pm 145.8 ; 3$ & $\pm 220.9 ; 5$ & $\pm 21.9 ; 5$ & $\pm 64.9 ; 5$ & $\pm 112.6 ; 4$ & $\pm 77.4 ; 5$ \\
$>382$ & 3131.2 & 2865.1 & 522.6 & 1434.5 & 1194.6 & 1531.3 \\
$\pm 1 \mathrm{SD} ; \mathrm{n}$ & $\pm 113.2 ; 4$ & $\pm 178.7 ; 3$ & $\pm 48.7 ; 5$ & $\pm 87.2 ; 5$ & $\pm 151.7 ; 4$ & $\pm 266.4 ; 3$ \\
$>403$ & 2952.4 & 2647.3 & 506.6 & 1450.2 & 1249.9 & 1811.1 \\
$\pm 1 \mathrm{SD} ; \mathrm{n}$ & $\pm 64.1 ; 4$ & $\pm 204.2 ; 4$ & $\pm 41.1 ; 5$ & $\pm 41.1 ; 3$ & $\pm 52.6 ; 4$ & $\pm 101.5 ; 5$ \\
\hline
\end{tabular}

fixed relative to the PAR treatment was enhanced with the addition of the entire UVA spectrum (Fig. 8A). The $>318 \mathrm{~nm}$ treatment resulted in the greatest $E_{\mathrm{UVA}}$ of $429 \mathrm{mg} \mathrm{C} \mathrm{m}^{-3} \mathrm{~h}^{-1}(\mathrm{p}=0.002,15 \%)$ relative to PAR for the $P$. australis community and a greater $E_{\mathrm{UVA}}$ than during any other experiment (Table 2, Fig. 8A). The addition of the UVB spectrum ( $>295 \mathrm{~nm}$ treatment) resulted in a $4 \%$ loss of fixed carbon relative to PAR $(p=0.23)$ for the Pseudo-nitzschia sp.-dominated community, though the difference is not statistically significant. During the LL experiment on the following day (June 9), primary productivity was enhanced relative to PAR only by the long wavelength portion of the UVA spec- trum $(>382$ and $>341 \mathrm{~nm})$ and was highest $(9 \% ; p=0.03)$ in the $>341 \mathrm{~nm}$ treatment. Both short wavelength UVA and UVB resulted in a net loss of carbon, with the greatest loss $(7 \%$; $=0.04)$ occurring in the $>295 \mathrm{~nm}$ treatment. Irradiances were the highest on June 13 and while addition of long wavelength UVA appeared to enhance primary production slightly, there was no statistical difference $(p=0.45)$ between the $>341$ and the $>403 \mathrm{~nm}$ treatment during the June 13 full-day experiment. UVB treatments resulted in the greatest loss of carbon fixed relative to PAR on June $13(\mathrm{p}=0.05)$.

The short-term incubation with the Pseudo-nitzschia sp. community on June 8 yielded trends in UV net effects similar to those observed during the full-day incubation (Fig. 8B). During the short incubation, the production rates were also enhanced in all UVA + PAR treatments, and $E_{\mathrm{UVA}}$ was greatest $(13.5 \% ; \mathrm{p}=0.02)$ at short UVA wavelengths (>318 nm treatment). However, $E_{\text {UVA }}$ seemed uniform across UVA and the difference in carbon fixation between the $>318$ and $>341 \mathrm{~nm}$ treatments was not statistically significant $(\mathrm{p}=0.27$; Table 2$)$. The $I_{\mathrm{UVB}}$ ranged between 2 and $9 \%$ loss of carbon fixation relative to the PAR treatment, but differences between the $>295 \mathrm{~nm}$ and PAR treatments were not statistically significant $(p=0.38)$. The following day (June 9), the spectral response during the short incubation again agreed well with observations from the full-day incubation. Only the long UVA wavelength treatments resulted in enhanced primary production (max. $E_{\mathrm{UVA}}$ at $>341 \mathrm{~nm}=9 \% ; \mathrm{p}=0.03$ ), while short wavelength UVA and UVB treatments resulted in loss of fixed carbon relative to PAR, ranging from 10 to $13 \%$. The enhancement in the long UVA (>341 nm) treatment was significantly different from the inhibition effect in the short UVA treatment $(>318 \mathrm{~nm})(\mathrm{p}<0.001)$. During the short-term experiment on June 13, all treatments resulted in a significant carbon loss compared to the PAR treatment (Fig. 8B, Table 2).

During each of the 6 incubations, the treatment with the full solar spectrum $(>295 \mathrm{~nm})$ resulted in the greatest inhibition of primary productivity (Fig. 8C,D). For the Pseudo-nitzschia sp. community on June 8, only 

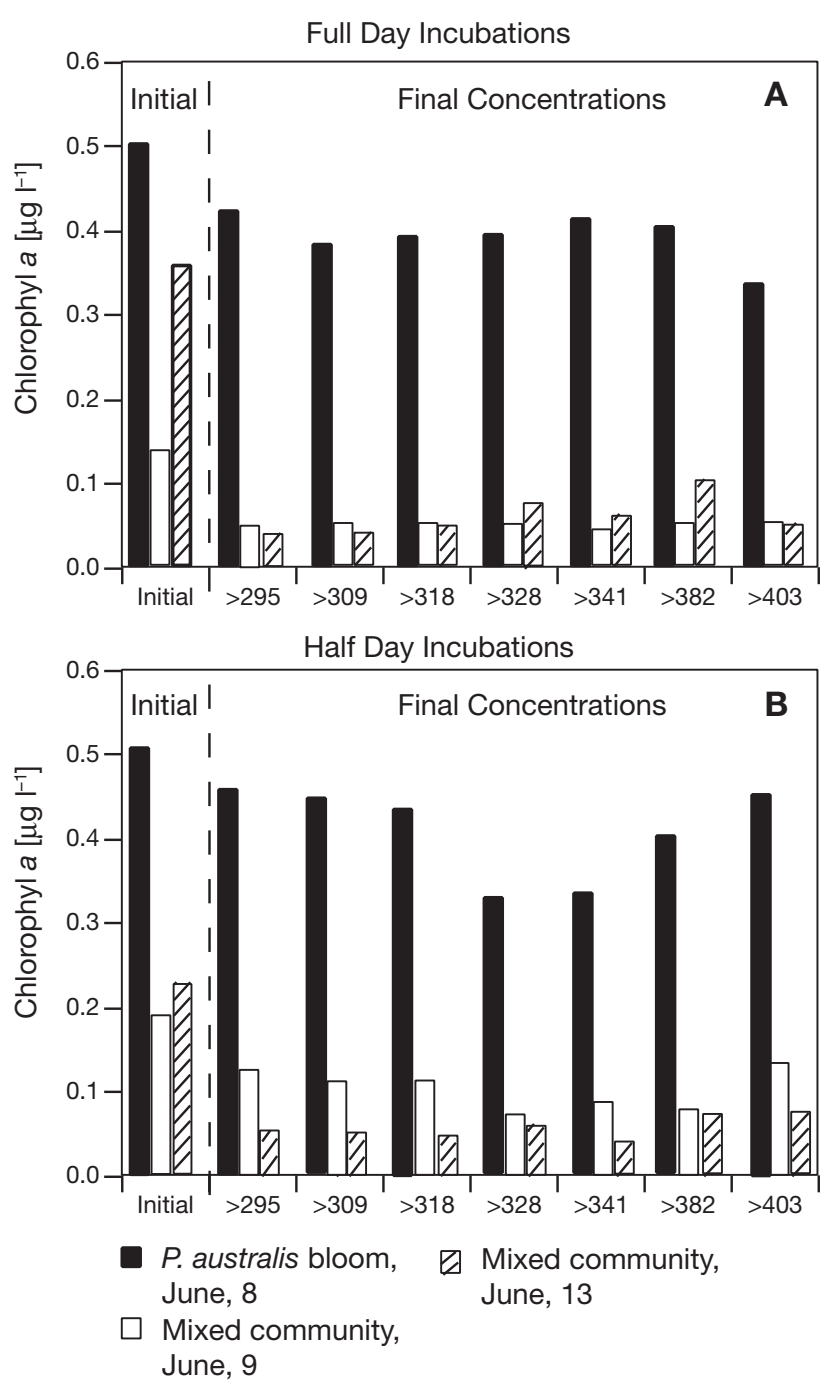

Fig. 7. Chl a concentration $\left(\mathrm{mg} \mathrm{l}^{-1}\right)$ in the initial sample and the final concentration in each light treatment (>295 through $>403 \mathrm{~nm}$ ) after (A) full-day incubations and (B) half-day incubations on June 8, 9 and 13, 1998

the $>295$ and $>309$ nm treatments, in which UVB was included in addition to UVA + PAR, resulted in an inhibition of primary productivity relative to the maximum rate observed in the $>318 \mathrm{~nm}$ treatment. The amount of carbon lost relative to the maximum carbon fixed (in the $>318 \mathrm{~nm}$ treatment $)$ was $17 \%(\mathrm{p}=0.01)$ for the $>295 \mathrm{~nm}$ treatment and $12 \%(\mathrm{p}<0.001)$ for the $>310 \mathrm{~nm}$ treatment during the full-day experiment and was slightly higher during the short-term incubation on June $8\left(I_{U V B}=14 \%, \mathrm{p}=0.02\right.$ and $I_{U V B}=20 \%, \mathrm{p}<$ 0.001 for the $>295$ and $>310 \mathrm{~nm}$ treatments, respectively). On June 9, the carbon lost relative to the maximum carbon fixed (in the $>341 \mathrm{~nm}$ treatment) ranged from 8 to $15 \%$ for the different spectral treatments during the full-day experiment, with the $>295 \mathrm{~nm}$ treatment again experiencing the greatest loss $(20 \%, \mathrm{p}=$
0.002). The full-day incubation on June 13, which received twice the irradiance of that on June 9, resulted in a similar $12 \%$ UVB inhibition of primary production relative to the maximum amount of carbon fixed ( $>295$ vs $>341 \mathrm{~nm}$ treatment, $\mathrm{p}=0.07$ ). During the short-term experiment on June 13, all UV treatments resulted in loss of carbon fixation relative to the PAR treatment ( $p \leq 0.01)$. The difference in sensitivity of primary productivity to high UV-irradiance between the shortterm and full-day experiment on June 13 could be a result of the time required for photorepair mechanisms to balance short-term damage.

\section{DISCUSSION}

Before the onset of our cruise in June 1998, an unusual marine mammal mortality event with DA poisoning symptoms along the central California coast led to a coordinated effort to collect offshore waters in order to document this event. The initial goal of our cruise was therefore to locate the Pseudo-nitzschia australis bloom in the Santa Barbara Channel, send requested samples for toxin analysis to V. Trainer's laboratory, and to conduct our UV experiments with the Pseudo-nitzschia bloom community. Previous samples collected by colleagues on June 4 and 5 in the Santa Barbara Channel led to the first observation of a toxic $P$. australis bloom in waters this far south of Monterey Bay (Trainer et al. 2000). More recent observations have documented the occurrence of toxic $P$. australis as far south as San Diego (Busse et al. 2005).

While the phytoplankton biomass had decreased from previous days, the algal community at the first experimental site was still dominated by diatoms, indicated by the $>70 \%$ FUCO contribution to total marker pigments (Fig. 7). Light microscopic observations of the net phytoplankton determined $90 \%$ of the assemblage was of the genus Pseudo-nitzschia, with some Chaetoceros sps. and dinoflagellates also present in the net phytoplankton. Weekly observations during 2004 in Santa Barbara coastal waters have revealed a very good correlation $\left(\mathrm{r}^{2}=0.81\right)$ between the abundance of $P$. australis and the genus Pseudo-nitzschia, which leads us to believe that most of the cells identified by light microscopy on June 8 were likely $P$. australis. Despite our efforts to remain in the same water mass, the community assemblage the following day changed to a mix of flagellates and diatoms (Fig. 7). Microscopic observations of the net phytoplankton revealed a mixed assemblage of diatoms, with representatives of the genera Pseudo-nitzschia, Chaetoceros and Thalassiosira, flagellates and some dinoflagellates of the genus Protoperidinum. On June 13, we were situated in a warm water mass at a different geo- 


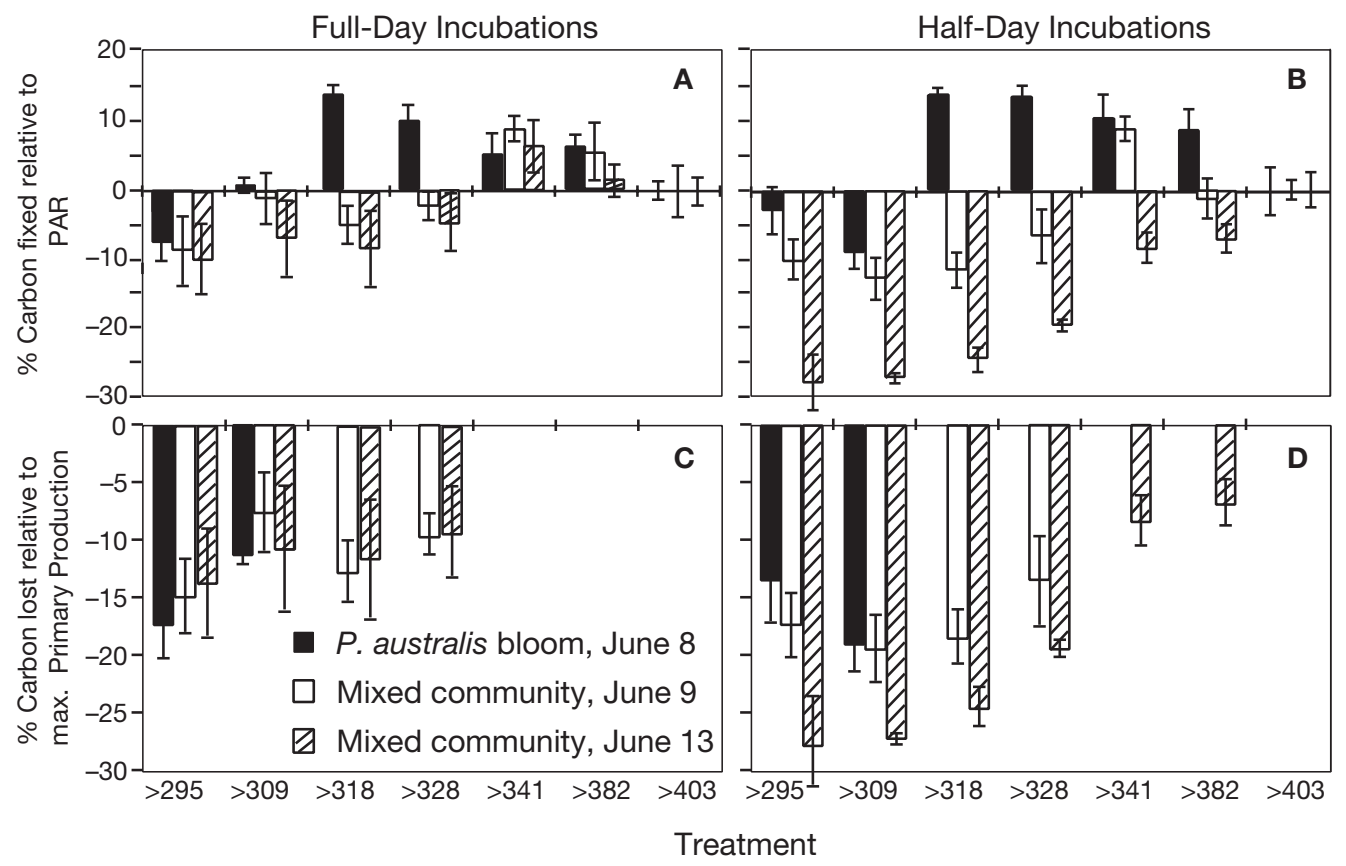

Fig. 8. Percent UVA enhancement and UVB inhibition of carbon production relative to the $>403 \mathrm{~nm}$ treatment (A) during full-day incubations on June 8, 9 and 13, 1998, and (B) during short-term incubations on June 8, 9 and 13,1998 , and the percent UV inhibition of carbon production relative to the maximum production (C) during full-day incubations on June 8, 9 and 13, 1998, and (D) during shortterm incubations on June 8, 9 and 13, 1998. Error bars represent the percentage error of the mean $(\mathrm{n}=5)$

Table 2. The difference between average spectral treatments $\left(\mathrm{mg} \mathrm{C} \mathrm{m}^{-3} \mathrm{~h}^{-1}\right)$ (negative values represent reduced carbon fixation rates relative to longer wavelength treatment) and the probability of the compared spectral treatments being equal ( $t$-test)

\begin{tabular}{|lcccccc|}
\hline \multirow{2}{*}{ Treatment } & June 8 & June 8 & June 9 & June 9 & June 13 & June 13 \\
& Full day & Half day & Full day & Half day & Full day & Half day \\
\hline$>295$ to $>400$ & -135.3 & -51.7 & -45.2 & -176.8 & -183.3 & -545.4 \\
p-value & 0.21 & 0.38 & 0.04 & 0.05 & 0.05 & $<0.001$ \\
$>318$ to $>400$ & 428.5 & 357.0 & -27.8 & -173.2 & -114.3 & -448.3 \\
p-value & 0.002 & 0.02 & 0.13 & 0.02 & 0.08 & $<0.001$ \\
$>341$ to $>400$ & 171.3 & 271.7 & 43.9 & 124.5 & 59.4 & -153.4 \\
p-value & 0.05 & 0.05 & 0.03 & 0.03 & 0.20 & 0.01 \\
$>318$ to $>341$ & 257.2 & 85.3 & -71.7 & -297.7 & -173.7 & -294.9 \\
p-value & 0.03 & 0.27 & 0.001 & $<0.001$ & 0.04 & $<0.001$ \\
\hline
\end{tabular}

graphic location, where the diagnostic carotenoids suggested a mixed algal assemblage, mostly comprised of diatoms, flagellates and chlorophytes (Fig. 7). The net phytoplankton was comprised predominantly of Chaetoceros spp., several species of the dinoflagellate genus Protoperidinum and unidentified flagellates.

The uniform loss in chl a across the light treatments is consistent with the notion that photobleaching is a function of overall light intensity due to the accumulation of reactive oxygen species (ROS) in the chloroplast (Barenyi \& Krause 1985). The decrease in chl a concentrations in all treatments likely represents a combination of photobleaching and loss of overall biomass. The HL and LL experiments with mixed communities, regardless of the difference in light exposure, resulted in greater loss of chl a than in the Pseudo-nitzschia sp. community, suggesting a greater sensitivity to photobleaching. Of course, grazing cannot be excluded as a contributing factor; however, we pre-screened samples prior to incubation with a $333 \mu \mathrm{m}$ mesh filter and the relative amount of phaeopigments did not change significantly from initials or between treatments.

UVA enhancement of carbon fixation for the Pseudo-nitzschia bloom community was highest in the treatment that includes the entire portion of the UVA spectrum (>320 nm) and the $E_{\mathrm{UVA}}$ at a given dose rate was significantly greater than for other mixed algal communities observed during 4 seasonal cruises (dataa not shown). In contrast, during the 4 experiments with the mixed algal communities, the benefit of UVA to carbon fixation was lost below wavelengths of $341 \mathrm{~nm}$ (on June 9) or even below $400 \mathrm{~nm}$ (on June 13) where the high energy UVA irradiance led to photoinhibition of carbon uptake. Although UVA has been described to enhance primary photochemistry in higher plants if PAR flux limits photosynthesis (Mantha et al. 2001, Johnson \& Day 2002), we assume that photosynthesis was not light-limited in our PAR only treatment. Rather, we propose that the addition of UVA improved carbon fixation due to the presence of pho- 
toreceptors in the UVA portion of the spectrum inducing photoprotective and photorepair mechanisms (Adamse et al. 1994, Portwich \& Garcia-Pichel 2000), and improving the balance between repair and damage processes (Cullen \& Lesser 1991, Prézelin et al. 1994, Lesser 1996). Short-wavelength UVA may play a role in the mycosporine-like amino acid (MAA) synthesis (Portwich \& Garcia-Pichel 2000) and in the case of Gyrodinium dorsum (dinoflagellate), was shown to have an action spectrum maximum for MAA synthesis at $310 \mathrm{~nm}$ (Klisch \& Häder 2002). UVA has also been found to induce gene expression of antioxidant genes (Dunlap \& Yamamoto 1995, Boldt \& Scandalios 1997) and to be important in photo-assisted repair of nucleic acid lesions (Mitchell \& Karentz 1993). Other studies describe indirect observations of improved photosynthetic rates with the addition of UVA or in some cases even with UVA + UVB (Nilawati et al. 1997, Gomez \& Figueroa 1998). Additionally, UVA enhancement in the Pseudo-nitzschia-dominated community may also be a result of a carbon-concentrating mechanism induced by UVA and blue light to minimize photodamage occurring under $\mathrm{CO}_{2}$ substrate limitation (Barenyi \& Krause 1985, Dionisio et al. 1989, Colman \& Rotatore 1995, John-McKay \& Colman 1997, Kaplan \& Reinhold 1999). High internal oxygen concentration resulting from oxygen evolution at PSII not only leads to high ROS but also competes with $\mathrm{CO}_{2}$ for Rubisco binding sites, potentially reducing carbon fixation due to photorespiration (Beardall 1989). Further work with pure cultures of $P$. australis or $P$. multiseries should aim at elucidating the role of UVA in these repair and photoprotective mechanisms, and in the potential role of a carbon-concentrating mechanism.

\section{Ecological significance}

The observed UVA enhancement for the Pseudonitzschia community is unique, in that it is greatest in the short-wavelength portion of the UVA spectrum and that it occurs at a relatively high dose rate. While enhanced carbon uptake does not necessarily translate into enhanced growth, experiments with cultures of $P$. multiseries resulted in growth inhibition only with the addition of the UVB irradiance, indicating that in this particular species, growth was not UVA-inhibited. Similar observations were also made for the polar diatom P. seriata (Nilawati et al. 1997), for which growth reduction was only observed in response to UVB.

In most water bodies (Kirk 1994), short-wavelength UV attenuates more rapidly with depth. Our experi- mental observations suggest that this particular Pseudo-nitzschia community could occupy a shallower depth stratum without being photoinhibited. At noon on June 8, UVB was fully attenuated below a depth of $18 \mathrm{~m}$, and UVA was fully attenuated below a depth of $40 \mathrm{~m}$ (Fig. 4). Hence, the mixed algal communities from June 13 would have been photoinhibited above a depth of $40 \mathrm{~m}$, whereas the Pseudo-nitzschia community photosynthesis would outperform over the 18 to $40 \mathrm{~m}$ depth range, representing $22 \mathrm{~m}$ or $38 \%$ of the biomass in the upper $100 \mathrm{~m}$ on June 8. Further work is necessary to determine whether the enhanced photosynthetic capability would translate into increased population growth, and whether Pseudo-nitzschia would outgrow other more UV-sensitive algal populations at those depths. Interestingly, at the time of our cruise, the depth of the chlorophyll maximum at the Pseudonitzschia sp.-dominated station was at a shallower light depth than most other chl a maxima observed during the 4 seasonal cruises.

Laboratory studies with additional Pseudo-nitzschia cultures and other diatom species will be necessary to assess whether this UV tolerance is truly unique to the genus Pseudo-nitzschia or more common among diatoms. Moreover, additional field observations need to confirm whether the UV enhancement of photosynthesis translates into growth enhancement. In many cases, physical factors will determine the vertical distribution of Pseudo-nitzschia blooms, making it difficult to test this hypothesis in situ. However, past accounts of Pseudo-nitzschia blooms in thin layers (Rines et al. 2002) and their association with modified upwelling (Trainer et al. 2000) should permit us to find these blooms in stratified waters where this physiological advantage might play a role and where the hypothesis could be tested further.

Acknowledgements. We thank the crew of the R/V 'Point Sur' for their support during data collection. We are also grateful for the invaluable assistance in the field of J. Roberts, T. McGovern, S. McKagan, and M. Gomez. Special thanks go to J. Gorga, who generously contributed the HPLC data. We greatly appreciate D. Siegel for providing the satellite images for sea surface temperature and chl a. We also thank the anonymous reviewers, whose comments helped improve the manuscript. Funding for this research was provided by the National Science Foundation (Grant \#OCE-9618390) to B.B.P., and C.M. was supported by a California Environmental Quality Initiative graduate fellowship (Award \#02T CEQI 08 0094).

\section{LITERATURE CITED}

Adamse P, Britz SJ, Caldwell CR (1994) Amelioration of UV-B damage under high irradiance: role of blue light photoreceptors. Photochem Photobiol 60:110-115

Barenyi B, Krause GH (1985) Inhibition of photosynthetic reactions by light. Planta 163:218-226 
Bargu S, Marinovic B, Mansergh S, Silver MW (2003) Feeding responses of krill to the toxin-producing diatom Pseudonitzschia. J Exp Mar Biol Ecol 284:87-104

Bates SS, Garrison DL, Horner RA (1998). Bloom dynamics and physiology of domoic-acid-producing Pseudo-nitzschia species. In: Anderson DM, Cembella AD, Hallegraeff GM (eds) Physiological ecology of harmful algal blooms. Springer-Verlag, Heidelberg, p 267-292

Beardall J (1989) Photosynthesis and photorespiration in marine phytoplankton. Aquat Bot 34:105-130

Boldt R, Scandalios JG (1997) Influence of UV-light on the expression of the Cat2 and Cat3 catalase genes in maize. Free Radical Bio Med 23:505-514

Bothwell ML, Sherbot D, Roberge AC, Daley RJ (1993) Influence of natural ultraviolet radiation on lotic periphytic diatom community growth, biomass accrual, and species composition: short-term versus long-term effects. J Phycol 29:24-35

Buma AGJ, Zemmelink HJ, Sjollema K, Gieskes WWC (1996) UVB radiation modifies protein and photosynthetic pigment content, volume and ultrastructure of marine diatoms. Mar Ecol Prog Ser 142:47-54

Busse LB, Venrick, EL, Antrobus R, Miller PE and 5 others (2005) Documentation of domoic acid in phytoplankton and fish in San Diego, California, USA. Harmful Algae (in press)

Collins CA, Garfield N, Rago TA, Rischmiller FW, Carter E (2000) Mean structure of the inshore countercurrent and California undercurrent off Point Sur, California. DeepSea Res II 47:765-782

Colman B, Rotatore C (1995) Photosynthetic inorganic carbon uptake and accumulation in two marine diatoms. Plant Cell Environ 18:919-924

Cullen JJ, Lesser MP (1991). Inhibition of photosynthesis by ultraviolet radiation as a function of dose and dosage rate: results for a marine diatom. Mar Biol 111:183-190

Dionisio ML, Tsuzuki M, Miyachi S (1989) Blue light induction of carbonic anhydrase activity in Chlamydomonas reinhardtii. Plant Cell Physiol 30:215-219

Dunlap WC, Yamamoto Y (1995) Small-molecule antioxidants in marine organisms: antioxidant activity of mycosporineglycine. Comp Biochem Phys 112B:105-114

Gomez I, Figueroa FL (1998) Effects of solar UV stress on chlorophyll fluorescence kinetics of intertidal macroalgae from southern Spain: a case study in Gelidium species. J Appl Phycol 10:285-294

Gulland F (1999) Unusual marine mammal mortality eventDomoic acid toxicity in California sea lions (Zalophus californianus) stranded along the central California coast, May-October 1998. NOAA Tech. Memo. NMFS-OPR-8. National Marine Fisheries Service, US Department of Commerce, Silver Springs, MD

Hargraves PE, Zhang J, Wang R, Shimizu Y (1993) Growth characteristics of the diatoms Pseudonitzschia pungens and Pseudonitzschia fraudulenta exposed to ultraviolet radiation. Hydrobiologia 269/270:207-212

Helbling EW, Villafane V, Ferrario M, Holm-Hansen O (1992) Impact of natural ultraviolet radiation on rates of photosynthesis and on specific marine phytoplankton species. Mar Ecol Prog Ser 80:89-100

Holm-Hansen O, Helbling E, Lubin D (1993) Ultraviolet radiation in Antarctica: inhibition of primary production. Photochem Photobiol 58:567-570

John-McKay ME, Colman B (1997) Variation in the occurrence of external carbonic anhydrase among strains of the marine diatom Phaeodactylum tricornutum (Bacillariophyceae). J Phycol 33:988-990
Johnson GA, Day TA (2002) Enhancement of photosynthesis in Sorghum bicolor by ultraviolet radiation. Physiol Plant 116:554-562

Kaplan A, Reinhold L (1999). $\mathrm{CO}_{2}$ concentrating mechanisms in photosynthetic microorganisms. Annu Rev Plant Mol Biol 50:539-570

Karentz D, Cleaver JE, Mitchell DL (1991) Cell survival characteristics and molecular responses of Antarctic phytoplankton to ultraviolet-B radiation. J Phycol 27:326-341

Kirk JTO (1994) Absorption of light within the aquatic medium. In: Kirk JTO (ed) Light and photosynthesis in aquatic ecosystems. Cambridge University Press, Cambridge, p 46-84

Klisch M, Häder DP (2002) Wavelength dependence of mycosporine-like amino acid synthesis in Gyrodinium dorsum. J Photoch Photobio B 66:60-66

Lefebvre KA, Dovel SL, Silver MA (2001). Tissue distribution and neurotoxic effects of domoic acid in a prominent vector species, the northern anchovy Engraulis mordaz. Mar Biol 138:693-700

Lesser MP (1996) Responses of phytoplankton acclimated to UV-B radiation: ultraviolet radiation absorbing compounds do not provide complete protection in the dinoflagellate, Prorocentrum micans. Mar Ecol Prog Ser 132:287-297

Lesser MP, Cullen JJ, Neale PJ (1994) Carbon uptake in a marine diatom during acute exposure to ultraviolet $\mathrm{B}$ radiation: relative importance of damage and repair. J Phycol 30:183-192

Madronich S, McKenzie RL, Bjorn LO, Caldwell MM (1998) Changes in biologically active ultraviolet radiation reaching the earth's surface. J Photoch Photobio B 46: $5-19$

Maldonado MT, Hughes MP, Rue EL, Wells ML (2002) The effect of $\mathrm{Fe}$ and $\mathrm{Cu}$ on growth and domoic acid production by Pseudo-nitzschia multiseries and Pseudo-nitzschia australis. Limnol Oceanogr 47:515-526

Mantha SV, Johnson GA, Day TA (2001) Evidence from action and fluorescence spectra that UV-induced violet-bluegreen fluorescence enhances leaf photosynthesis. Photochem Photobiol 73:249-256

Mitchell DM, Karentz D (1993) The induction and repair of DNA photodamage in the environment. In: Young AR, Bjorn LO, Moan J, Nultsch W (eds) Environmental UV photobiology. Plenum Press, New York, p 345-377

Mos L (2000) Domoic acid: a fascinating marine toxin. Environ Toxicol Phar 9:79-85

Neale PJ, Lesser MP, Cullen JJ (1994) Effects of ultraviolet radiation on the photosynthesis of phytoplankton in the vicinity of McMurdo Station, Antarctica. In: Weiler CS, Penhale PA (eds) Ultraviolet radiation in Antarctica: Measurements and biological effects. Antarctic Research Series, 62, American Geophysical Union, Washington, DC, p 125-142

Nilawati J, Greenberg BM, Smith REH (1997) Influence of ultraviolet radiation on growth and photosynthesis of two cold ocean diatoms. J Phycol 33:215-224

Pan Y, Subba Rao DV, Mann KH (1996) Acclimation to low light intensity in photosynthesis and growth of Pseudonitzschia multiseries Hasle, a neurotoxigenic diatom. J Plankton Res 18:1427-1438

Portwich A, Garcia-Pichel F (2000) A novel prokaryotic UVB photoreceptor in the cyanobacterium Chlorogloeopsis PCC 6912. Photochem Photobiol 71:493-498

Prézelin BB, Boucher NP, Smith RC (1994) Icecolors '90: marine primary production under the Antarctic ozone hole. In: Weiler CS, Penhale PA (eds) Ultraviolet radiation in Antarctica: measurements and biological effects. Antarc- 
tic Research Series, 62, American Geophysical Union, Washington, DC, p 159-186

Quesada A, Mouget JA, Vincent WF (1995) Growth of Antarctic cyanobacteria under ultraviolet radiation: UVA counteracts UVB inhibition. J Phycol 31:242-248

Rines JEB, Donaghay PL, Dekshenieks MM, Sullivan JM, Twardowski MS (2002). Thin layers and camouflage: hidden Pseudo-nitzschia (Bacillariophyceae) populations in a fjord in the San Juan Islands, Washington, USA. Mar Ecol Prog Ser 225:123-137

Scholin CA, Gulland et al (2000) Mortality of sea lions along the central California coast linked to a toxic diatom bloom. Nature 403:80-84

Smith RC, Prézelin BB, Baker KS, Bidigare RR and 9 others (1992) Ozone depletion: ultraviolet radiation and phytoplankton biology in Antarctic waters. Science 255:952-959

Trainer VL, Adams NG, Bill BD, Stehr CM, Wekell JC, Moeller P, Busman M, Woodruff D (2000) Domoic acid

Editorial responsibility: Victor de Jonge (Contributing Editor), Groningen, The Netherlands production near California coastal upwelling zones, June 1998. Limnol Oceanogr 45:1818-1833

Vincent WF, Roy S (1993) Solar ultraviolet-B radiation and aquatic primary production: damage, protection and recovery. Environ Rev 1:1-12

Work TM, Beale AM, Fritz L, Quilliam MA, Silver M, Buck KR, Wright JLC (1993) Domoic acid intoxication of brown pelicans and cormorants in Santa Cruz, California. In: Smayda TJ, Shimizu Y (eds) Toxic phytoplankton blooms in the sea. Elsevier, Amsterdam, p 643-649

Wright SW, Jeffrey SW (1997) High-resolution HPLC system for chlorophylls and carotenoids of marine phytoplankton. In: Jeffrey SW, Mantoura R, Wright SW (eds) Phytoplankton pigments in oceanography: guidelines to modern methods. UNESCO Publishing, Paris, p 327-341

Zudaire L, Roy S (2001) Photoprotection and long-term acclimation to UV radiation in the marine diatom Thalassiosira weissflogii. J Photoch Photobiol B 62:26-34

Submitted: August 17, 2004; Accepted: April 10, 2005 Proofs received from author(s): September 25, 2005 